pheric pressure a heat release rate of more than $120 \times 10^{6}\left(\mathrm{kcal} / \mathrm{m}^{3} \mathrm{~h}\right)$ or about $7.5 \times 10^{6}(\mathrm{BTU} /$ $\mathrm{ft}^{3} \mathrm{~h}$ ) at a pressure loss of half an atmosphere. $\mathrm{A}$ smaller chamber (half the linear dimensions) of the same type still came to about $450 \times 10^{6}$ (kcal $/ \mathrm{m}^{3} \mathrm{~h}$ ) with a velocity of about $100 \mathrm{~m} / \mathrm{s}$ of the air entering it.

\section{REFERENCES}

1. Damköhler, G.: Z. f. Elektrochemie, 46,601 (1940).

2. Karlovitz, B.: Fourth Symposium (International) on Combustion, p. 60. Baltimore, The Williams \& Wilkins Co., 1953.
3. REICHARDT, H.: Gesetzmässigkeit der freien Turbulenz. Berlin, VDI-Forschungsheft 414 , 1942.

4. Fage, A., and Falkner, V. M.: Proc. Roy. Soc., A135, 685 (1932).

5. Elias, F.: Die Wärmeübertragung einer geheizten Platte an strömende Luft, p. 9. Aachener Abhandlungen, 1930.

6. Lonenz, H.: Z. techn. Physik, 15, 376 (1934).

7. Schlichting: Grenzschicht-Theorie. Karlsruhe, 1951.

8. Swain, L. M.: Proc. Roy. Soc. (London), A125, $647(1929)$.

\title{
CORRELATION OF AUTOIGNITION PHENOMENA IN INTERNAL COMBUSTION ENGINES AND RAPID COMPRESSION MACHINES
}

\author{
By J. C. LIVENGOOD and P. C. WU
}

\section{Introduction}

The self-ignition of heated and compressed fuelair mixtures has been the object of much study, particularly in recent years. As a consequence of this wide-spread interest, data have become available from a variety of different kinds of apparatus. It is the purpose of this article to examine some of the possible relationships between these several kinds of results. A successful correlation is demonstrated which is based upon the gross parameters of a hypothetical chemical reaction.

\section{Definitions}

The self-ignition of a homogeneous mixture of fuel and air is herein defined as autoignition in order to differentiate this phenomenon from those which involve ignition by spark or from hot surfaces, or self-ignition phenomena involving evaporation and mixing processes. It has been widely demonstrated that the chemical reactions which lead to the eventual ignition of such a fuel-air mixture require a finite time interval. This time interval is, in general, a complex function of the physical state, as defined by the temperature and pressure, of the mixture and of its chemical constitution. For the special case wherein the physical state of the fuel-air mixture can be regarded as constant, this time interval has been called ignition delay, or simply, delay. It has been given the symbol, $\tau$.

\section{Experimental Measurements of Autoignition}

RAPID COMPRESSION MACHINES

Special devices ${ }^{1-6}$, known as rapid compression machines, have been constructed for the purpose of closely simulating the constant physical state reaction mentioned above. By their use it is possible to elevate quickly the temperature and pressure of a test mixture of fuel and air, and to allow the mixture to remain at this elevated state for the duration of the delay period. For extremely small values of delay (measured from the end of the compression process), an appreciable amount of reaction may occur during compression and thus the ideal concept of delay is not strictly applicable. The measurements which have been reported by investigators using these devices are listed in Table 1.

Figure 1 shows a typical pressure-time record from the M. I. T. Rapid Compression Machine. From this figure it can be seen that the physical state (as evidenced by pressure) is constant during the delay period. Some fuels show appreciable departure from this behavior. This problem will be discussed later. 


\section{MOTORED ENGINES}

While the special rapid compression machine thus permits an evaluation of the autoignition behavior of a fuel-air mixture as a function of its physical state, the application of such devices has been limited by the complexity and special nature of the apparatus, and by the relatively slow rate of production of data which can be obtained. A much simpler procedure for studying autoignition reactions is the use of a motored engine in which the fuel-air charge is compressed (and subsequently expanded) continuously ${ }^{7-10}$. Measurements which have been reported are listed in Table 1. An important disadvantage of this method is that the reactions are carried out in a continuously changing physical environment. This fact causes difficulty in the separation of autoignition of the end gas results from its rapid compression by both the piston and by expansion of the burned portion of the charge behind the flame front.

The various kinds of measurement which have been reported of the autoignition phenomenon in running engines are listed in Table 1.

\section{Temperature Measurements}

It is well recognized that the reactions of autoignition are very sensitive to temperature. In the rapid compression machine and in the motored engine the charge is well mixed and is reasonably homogeneous with regard to temperature and pressure. With careful measurements the approximate charge temperature can be estimated, perhaps, within $20^{\circ} \mathrm{F}$. However, in a firing engine

Table 1. Reported Measurements in Regearch on Autoignition in Rapid-Compression Machine, Motored Engine, and Firing Engine

\begin{tabular}{|c|c|c|c|c|c|c|c|c|c|c|c|}
\hline Apparatus & Pressure & $\begin{array}{c}\text { Temper- } \\
\text { ature } \\
\text { from Gas } \\
\text { Law }\end{array}$ & $\begin{array}{c}\text { Temper- } \\
\text { ature of } \\
\text { End Gas } \\
\text { from } \\
\text { Sound } \\
\text { Velocity }\end{array}$ & $\mid \begin{array}{l}\text { Temper- } \\
\text { ature of } \\
\text { End Gas } \\
\text { from Ab- } \\
\text { sorption } \\
\text { Spectra }\end{array}$ & $\begin{array}{c}\text { Chemical } \\
\text { Analysis } \\
\text { via } \\
\text { Sample }\end{array}$ & $\begin{array}{c}\text { Chemical } \\
\text { Analysis } \\
\text { via } \\
\text { Specto- } \\
\text { graph }\end{array}$ & $\begin{array}{c}\text { Cool } \\
\text { Flame } \\
\text { Detection }\end{array}$ & $\begin{array}{c}\text { Time } \\
\text { Measure- } \\
\text { ment }\end{array}$ & $\begin{array}{c}\text { Un- } \\
\text { burned } \\
\text { Specific } \\
\text { Volume } \\
\text { of End } \\
\text { Gas }\end{array}$ & $\begin{array}{l}\text { Flame } \\
\text { Photo- } \\
\text { graph }\end{array}$ & $\begin{array}{l}\text { Schlieren } \\
\text { Photo- } \\
\text { graph }\end{array}$ \\
\hline $\begin{array}{l}\text { Rapid-compres- } \\
\text { sion machine }\end{array}$ & $X$ & $\mathrm{X}$ & & & & & & $\mathbf{X}$ & & $\mathrm{X}$ & $\mathrm{X}$ \\
\hline Motored engine & $\mathrm{X}$ & $\mathrm{X}$ & & & $\mathbf{X}$ & $\mathrm{X}$ & $\mathrm{X}$ & $\mathbf{X}$ & $\mathrm{X}$ & & \\
\hline Firing engine & $\mathrm{X}$ & $\mathrm{X}$ & $\mathbf{X}$ & $\mathrm{X}$ & $\mathrm{X}$ & $\mathrm{X}$ & & $\mathbf{X}$ & $\mathbf{X}$ & $\mathbf{X}$ & $\mathbf{X}$ \\
\hline
\end{tabular}

$\mathrm{X}=$ Having reported data.

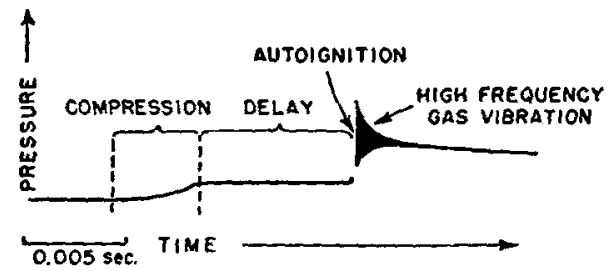

FIG. 1. Typical pressure-time record for rapid compression of stoichiometric mixture of $n$-heptane and air. (M.I.T. Rapid Compression Machine.)

variables when an analysis of results is undertaken.

\section{FIRING ENGINE}

One of the problems which has stimulated much of the activity in the study of autoignition is the phenomenon of knock, or detonation, in the spark ignition internal combustion engine. One widely accepted interpretation of this occurrence is that it results from the autoignition of an unburned part of the fresh charge (end gas). This the temperature of the end gas cannot be accurately estimated from pressure measurements and using the gas law, because of uncertainties in estimating the end gas volume and also because of the relatively large heat-transfer effects. However, recent developments now permit the determination of end-gas temperatures by a technique which measures the velocity of propagation of sound ${ }^{11,}{ }^{12}$.

These measurements have been accomplished in a laboratory engine (Fig. 2) equipped with transducers mounted on opposite sides of the end gas zone. Special instrumentation accomplishes accurate measurement of the transit time of high frequency sound pulses which are projected through the end gas.

When the end-gas composition is known with suitable accuracy (this is usually the case) its temperature can be computed from the classical relationship

$$
T=\frac{M c^{2}}{\gamma R}
$$


where $T=$ absolute temperature of the end gas $M=$ average molecular weight of the end gas

$c=$ average velocity of sound through end gas

$\gamma=$ average value of specific heat ratio of end gas

$R$ = universal gas constant

In its present state of development this temperature determination can be made within $20^{\circ} \mathrm{F}$ or better.

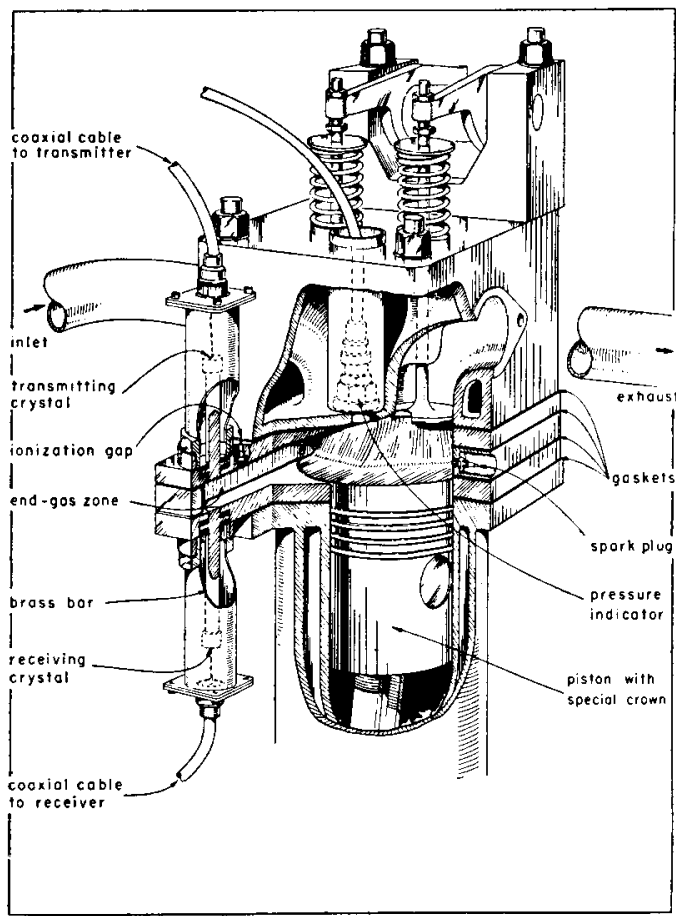

FIG. 2. CFR Engine with special instrumentation for measuring the velocity of sound in the end gas.

\section{Common Features of Autoignition in Different Apparatus}

An examination of Table 1 reveals those areas where there is sufficient overlapping of information to support an attempt at a quantitative correlation of the various kinds of results. It is apparent that the best represented data are those which present the autoignition process as a function of pressure, temperature and time. The other measurements serve as aids in estimating the useful limits of assumptions, etc., but until the same techniques have been applied to many kinds of experiment their general utility cannot be appraised.

\section{The Relationship of Delay to Engine Knock}

Perhaps the greatest difficulty encountered in attempting a correlation between the results from a rapid compression machine and a firing (or motored) engine is the great difference in statetime history which is produced in the fuel-air mixture. This is, of course, true even when the initial and final states are the same.

Consequently, in order to interpret engine behavior in terms of rapid compression machine results, it is necessary to devise a correlation scheme which accounts for the changing environment to which the fuel-air mixture is subjected in the engine. If the details of the reactions which precede autoignition were known, this might be accomplished. However, as has been suggested ${ }^{13}$, it may be practicable to assume that an equivalent aggregate reaction will describe the process insofar as the end result is concerned, provided that it can be further assumed that the reactions are of the same kind in rapid-compression machine, motored engines, and firing engines ${ }^{a 15}, 16$. The gross parameters of such a reaction might have the following general form:

$\frac{d(x)}{d t}=\phi_{1}(p, T, t)$

$$
\phi_{2}(F, \text { chemical composition, etc.) }
$$

where $(x)=$ concentration of pertinent reaction products

$t=$ time

$p=$ absolute pressure

$T=$ absolute temperature

$\phi_{1}, \phi_{2}=$ empirical functions

$F=$ fuel-air ratio

Equation (1) thus implies that, for a given fuelair mixture there exists a fixed functional relationship between the rate of the aggregate reaction, the instantaneous physical state, and time. It can be assumed further that the ultimate consequence of the gross reaction of equation (1) is a sudden transition to a process which then proceeds to complete the combustion reaction within a time interval which is smaller by orders of magnitude than the preceding delay period. This assumed behavior yields the concept of a critical value for the concentration, $(x)_{c}$.

This concept of a critical concentration pro-

${ }^{a}$ An analogous procedure has been used by Strickland-Constable ${ }^{14}$ to predict the ignition temperature of the gases following the pre-heat zone in a flame. 


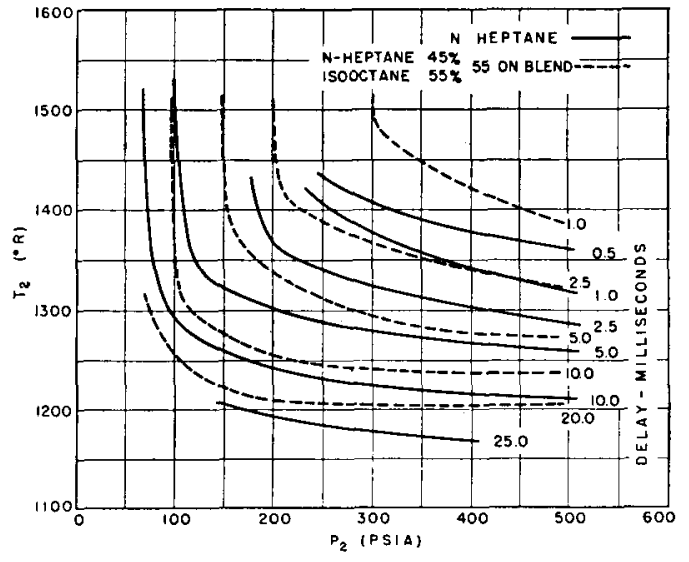

FIG. 3. Ignition delay as a function of temperature and pressure for two fuel-air mixtures.

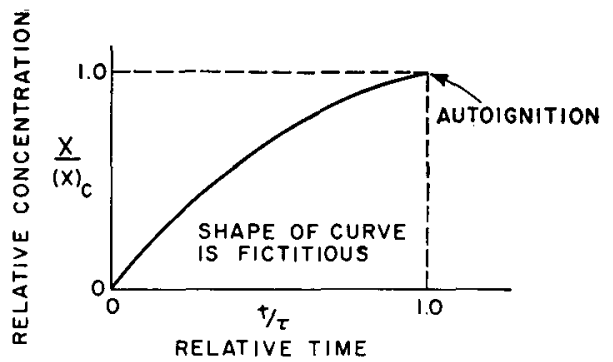

FIg. 4. Hypothetical behavior of preliminary reactions in rapid compression machine processes, each of which is carried out at some particular temperature and pressure. Initial chemical composition of the fuel-air mixture is assumed to be constant.

(a)

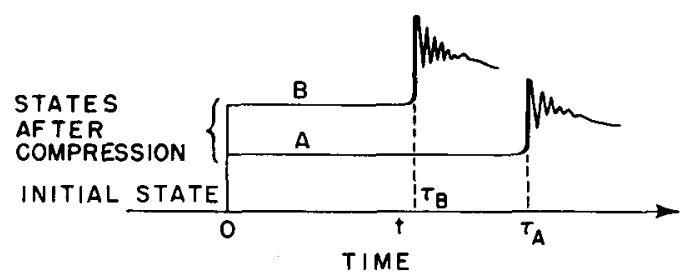

(b)

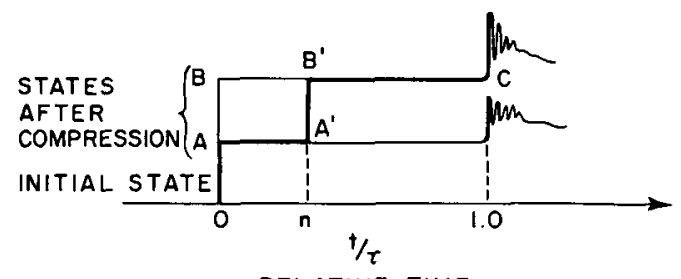

RELATIVE TIME

FIG. 5. (a) Hypothetical state-time paths of rapid compression machine processes $A$ and $B$. (b) Same processes plotted on the $t / \tau$ base, with the line $\mathrm{OAA}^{\prime} \mathrm{B}^{\prime} \mathrm{C}$ showing a "stepped" process. vides a limit for an integration process during which the concentration of chain carriers builds up. Hence, once the relationship between physical state and the low speed reaction rate is known, and the critical limit is determined, it should be possible to predict the time of occurrence of the high speed explosion during any state-time process for the fuel-air mixture in question.

This relationship has been studied and reported in the form of ignition delay data for various fuels. Often these data appear as empirical coefficients and exponents in the general form:

$$
\tau=c e^{(-b / \boldsymbol{T}) p^{n}}
$$

where $\tau=$ ignition delay

$T=$ mixture temperature

$p=$ mixture pressure

$c, b, n=$ empirical constants

However, for the usual engine fuels, it has been found that this form of equation is adequate only over a limited range of temperature for any particular pressure ${ }^{17},{ }^{18}$. For this reason it is convenient to present such data in graphical form.

Two such graphs are shown in Figure 3 . The fuels were $n$-heptane and a blend of $n$-heptane and isooctane $(2,2,4$ trimethylpentane), and they were tested in a stoichiometric mixture with air in the M. I. T. Rapid Compression Machine. The estimated accuracy of the location of the isodelay lines is $\pm 20^{\circ} \mathrm{F}$ and $\pm 10 \mathrm{psi}$. The isodelay contours were estimated from Arrhenius plots at various pressures, and the interpolated delay values are within ten per cent. The percentage dispersion of individual test results is of the same order of magnitude except for the very long (25 msec) delay values. In this region occasional test mixtures did not react to completion.

\section{The Relationship between Ignition Delay and Reaction Rate}

The reasoning used in the discussion of the reactions in the end gas can be applied with the same approximations to the fixed state process in the rapid compression machine. The assumptions are shown diagrammatically in Figure 4. The curved line implies that the most general assumption is that the reaction rate is not necessarily constant during the delay period. The assumption that there is a functional relationship between the concentration ratio, $(x) /(x)_{c}$, and the relative time, $t / \tau$, is simply another way of describing the following assumed behavior of a particular fuelair mixture in the rapid compression machine. 
If two experiments were performed at different states, $A$ and $B$, then the state-time diagrams would appear as shown in Figure 5a. If a third experiment could be performed, employing a stepped compression path, $O-A-A^{\prime}-B^{\prime}$ in Figure $5 \mathrm{~b}$, then the overall reaction time (delay cannot be used here, since that term has been reserved for constant state reactions) will be:

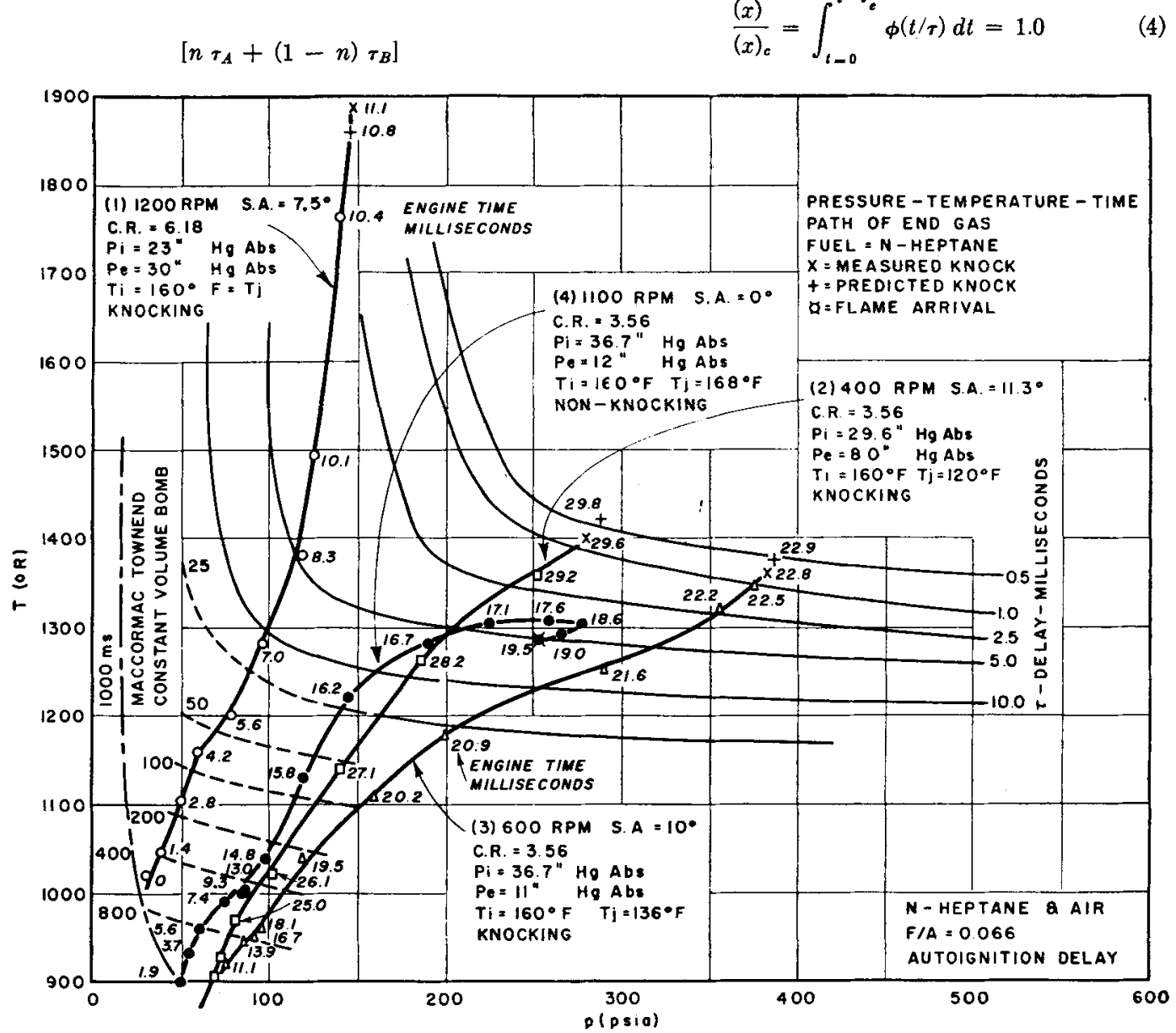

Fig. 6. Temperature-pressure-time paths of the end gas in a firing engine superimposed on auto ignition delay "map" for the same fuel-air mixture. (Dotted lines are extrapolations.)

where $n$ is the time fraction of $t / \tau$ which elapsed (at state $A$ ) before the next step of the compression to state $B$. This expression for the reaction time of this stepped process is applicable regardless of the form of the functional relationship between $(x) /(x)_{c}$ and $t / \tau$. This reasoning also implies that the denominator, $(x)_{c}$, in the ordinate scale of Figure 4 must be assumed a constant. Otherwise the step from $A^{\prime}$ to $B^{\prime}$ in Figure $5 \mathrm{~b}$, although completed in zero time, would involve a change in $(x)$. This kind of change must be disallowed, since a shift to a high speed reaction has been reserved as the definition of the end of the delay period. Thus it can be assumed that

$$
\frac{d}{d t}\left[\frac{(x)}{(x)_{c}}\right]={ }_{\phi}\left(\frac{t}{\tau}\right)
$$

From equation (3) it follows that

$$
\frac{(x)}{(x)_{c}}=\int_{t-0}^{t-t_{e}} \phi(t / \tau) d t=1.0
$$


tion delay data and a knowledge of the state-time history of the process in question.

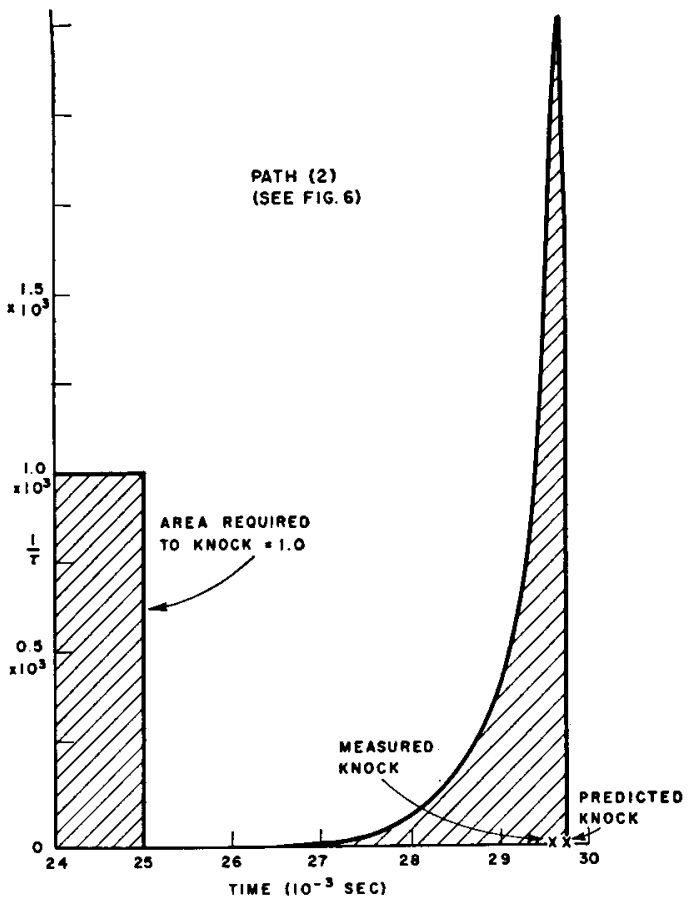

Frg. 7. Graphical integration for the prediction of knock in a firing engine.

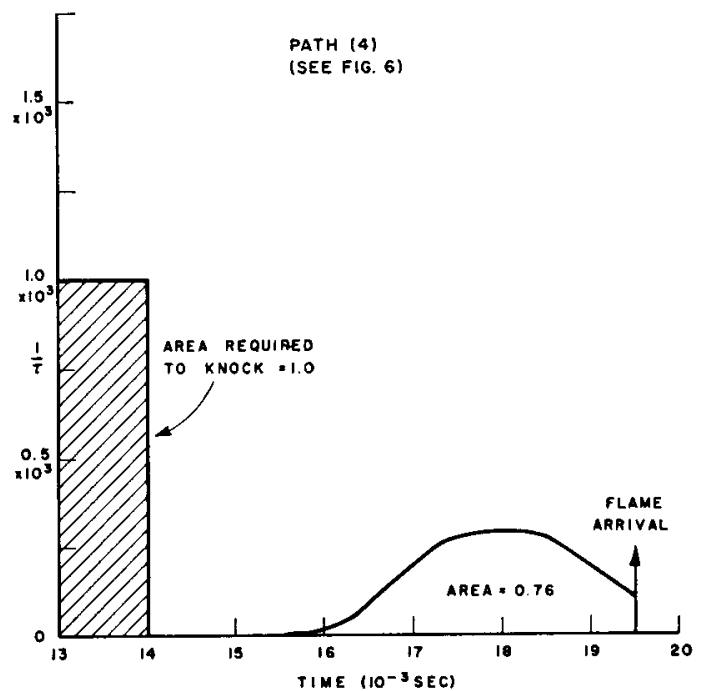

FIG. 8. Graphical integration scheme applied to a knock-free engine cycle.

\section{Application of the Integration to a Firing Engine}

As was mentioned earlier, the end gas temperature-time history can now be measured accurately by the velocity of sound technique, and pressuretime records of good precision are also available. From these data it is possible to define the temperature-pressure path followed by the end gas, and along this path to indicate the corresponding time intervals. Several such curves are shown in Figure 6, where the engine temperature-pressure paths have been superimposed on one of the autoignition maps of Figure 3. Shown also is the one second constant delay line obtained in a constant volume bomb ${ }^{19}$. From the intersections of these engine paths with the isodelay contours from the rapid compression machine, the information needed to solve equation (5) can be obtained.

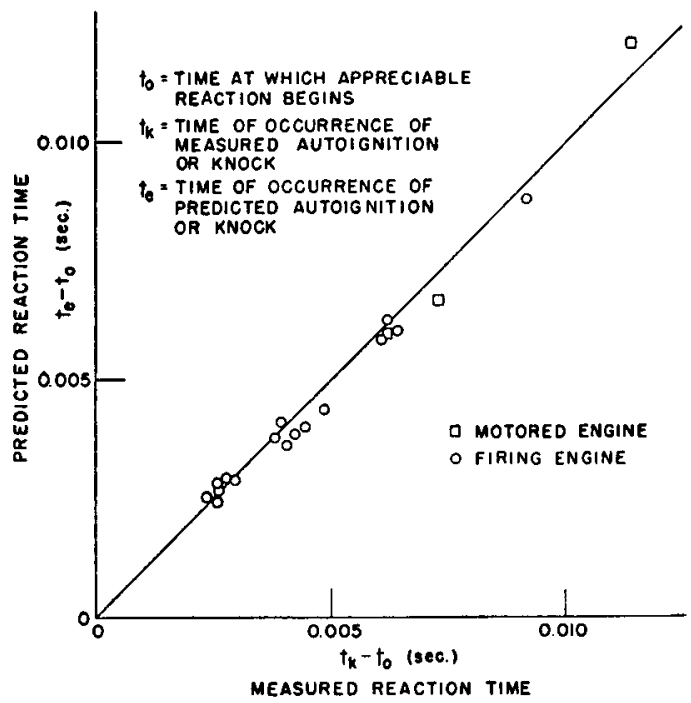

FIG. 9. Correlation between prediction and measurement of the time of autoignition. Plot includes both motored and firing engine cycles.

This integration has been performed graphically, as shown in Figure 7, for example. There is, of course, the problem of choosing the zero for the engine time-scale. This choice is an arbitrary one, but it is not critical provided it is placed at such a low temperature and pressure that the corresponding reaction rates are very low (long delay). In Figure 7, for example, it is apparent that the zero time point for the engine could have been placed 27 msec later in the engine cycle with no effect upon the integration and predicted autoignition. This time, at which appreciable reaction begins, has been called $t_{0}$.

Figure 8 shows this kind of integration for an engine cycle which was knock-free. As might be 
expected, the normal flame consumed the end gas before autoignition occurred. In this instance the
Similar experiments have been performed over a wide range of conditions, using both $n$-heptane

Table 2. Prediction of Autoignition or Knock in Motored and Firing CFr Engines Motored CFR Engine: (Data and computations kindly supplied by E. B. Rifkin and C. Walcutt through courtesy of Ethyl Corporation)

Fuel : $n$-heptane, $\quad \mathrm{F} / \mathrm{A}=0.066, \quad$ Mixture Temperature $=150^{\circ} \mathrm{F}$

\begin{tabular}{|c|c|c|c|c|c|c|c|c|c|c|c|c|c|c|c|c|}
\hline \multirow{2}{*}{ Run } & \multirow{2}{*}{ Speed } & \multirow{2}{*}{ C.R. } & \multirow{2}{*}{$\begin{array}{l}\text { Throt- } \\
\text { tle }\end{array}$} & \multicolumn{3}{|c|}{$\begin{array}{l}\text { Earliest Predicted } \\
\text { Significant Reaction }\end{array}$} & \multicolumn{3}{|c|}{$\begin{array}{l}\text { Observed Cool } \\
\text { Flame }\end{array}$} & \multicolumn{3}{|c|}{ Observed Autoignition } & \multicolumn{3}{|c|}{ Predicted Autoignition } & \multirow{2}{*}{$\begin{array}{c}\text { Time } \\
\text { Difference } \\
\text { between } \\
\text { Prediction } \\
\text { and Meas- } \\
\text { urement, } \\
t_{e}-t_{k}\end{array}$} \\
\hline & & & & $t_{0}$ & $p$ & $T$ & Time & $p$ & $T$ & $t_{k}$ & $p$ & $T$ & $t_{e}$ & $p$ & $T$ & \\
\hline & $r p m$ & & & $\begin{array}{l}10^{-3} \\
\sec \end{array}$ & psia & ${ }^{\circ} R$ & $\begin{array}{l}10^{-3} \\
\sec \end{array}$ & psia & ${ }^{\circ} \mathrm{R}$ & $\begin{array}{l}10^{-3} \\
\sec \end{array}$ & psia & ${ }^{\circ} R$ & $\begin{array}{l}10^{-3} \\
\mathrm{sec}\end{array}$ & psia & ${ }^{\circ} R$ & $10^{-8} \mathrm{sec}$ \\
\hline 1 & 600 & 5.54 & Open & 24 & 77 & 1115 & 30.5 & 117 & 1230 & 35.4 & 132 & 1355 & 35.9 & 133 & 1380 & +0.5 \\
\hline 2 & 900 & 5.65 & Open & 18 & 95 & 1202 & 20.4 & 123 & 1265 & 24.2 & 134 & 1450 & 24.0 & 133.5 & 1425 & -0.3 \\
\hline 3 & 1200 & 6.53 & Part & 7.5 & 55 & 1160 & 11.0 & 103 & 1350 & 14.8 & 170 & $>1900$ & 14.1 & 154 & 1900 & -0.7 \\
\hline
\end{tabular}

Firing CFR Engine: (Sloan Laboratory for Automotive and Aircraft Engines)

Fuel: Run 1-9-n-heptane, Run 10-17-n-heptane, Iso-octane blend 55 octane number, F/A $=0.0665$

\begin{tabular}{|c|c|c|c|c|c|c|c|c|c|c|c|c|c|c|c|}
\hline \multirow{2}{*}{ Run } & \multirow{2}{*}{ Speed } & \multirow{2}{*}{ C. $\mathbf{R}$. } & \multirow{2}{*}{$T_{i}$} & \multirow{2}{*}{$p_{i}$} & \multirow{2}{*}{ S.A. } & \multicolumn{3}{|c|}{$\begin{array}{l}\text { Earliest Predicted } \\
\text { Significant Reaction }\end{array}$} & \multicolumn{3}{|c|}{ Observed Knock } & \multicolumn{3}{|c|}{ Predicted Knock } & \multirow{2}{*}{$\begin{array}{c}\text { Time } \\
\text { Difference } \\
\text { between } \\
\text { Prediction } \\
\text { and Meas- } \\
\text { urement, } \\
t_{e}-t_{k}\end{array}$} \\
\hline & & & & & & $t_{0}$ & $p$ & $T$ & $\iota_{k}$ & $p$ & $T$ & te & $p$ & $T$ & \\
\hline & $r p m$ & & ${ }^{\circ} \mathrm{F}$ & $p s i a$ & ${ }^{\circ} \mathrm{BTC}$ & $10^{-3} \mathrm{sec}$ & psia & ${ }^{\circ} R$ & $10^{-3} \mathrm{sec}$ & psia & ${ }^{\circ} R$ & $10^{-3} \mathrm{sec}$ & $p s i a$ & ${ }^{\circ} R$ & $10^{-8} \mathrm{sec}$ \\
\hline 1 & 1200 & 6.18 & 160 & 11.3 & 7.5 & 5 & 70 & 1180 & 11.1 & 150 & 1900 & 10.8 & 147 & 1870 & -0.3 \\
\hline 2 & 400 & 3.56 & 160 & 14.5 & 11.3 & 27 & 135 & 1130 & 29.6 & 280 & 1390 & 29.8 & 286 & 1415 & +0.2 \\
\hline 3 & 600 & 3.56 & 160 & 13.1 & 10 & 20 & 145 & 1090 & 22.8 & 380 & 1630 & 22.9 & 385 & 1380 & +0.1 \\
\hline 4 & 1100 & 3.56 & 160 & 18.0 & 0 & 15.5 & 120 & 1110 & & & \multicolumn{4}{|c|}{ Non-knocking } & \\
\hline 5 & 900 & 6.18 & 160 & 10.3 & 10 & 5 & 60 & 1090 & 14.2 & 260 & 1900 & 13.8 & 205 & 1800 & -0.4 \\
\hline 6 & 600 & 6.18 & 160 & 12.4 & 5 & 15 & 110 & 1160 & 21.0 & 270 & 1400 & 21.4 & 295 & 1425 & +0.4 \\
\hline 7 & 400 & 3.56 & 160 & 14.6 & 10 & 23 & 110 & 1050 & 26.2 & 300 & 1410 & 26.3 & 305 & 1420 & +0.1 \\
\hline 8 & 1200 & 3.56 & 160 & 18.7 & 15 & 9 & 100 & 1055 & 11.4 & 243 & 1425 & 11.5 & 250 & 1430 & +0.1 \\
\hline 9 & 900 & 3.56 & 160 & 19.2 & 10 & 13 & 120 & 1075 & 15.6 & 302 & 1410 & 15.4 & 290 & 1400 & -0.2 \\
\hline 10 & 500 & 3.56 & 160 & 20.9 & 15 & 20.3 & 165 & 1110 & 23.3 & 417 & 1485 & 23.2 & 408 & 1480 & -0.1 \\
\hline 11 & 600 & 5.08 & 160 & 17.5 & 6 & 18 & 143 & 1120 & 22.5 & 420 & 1750 & 22.0 & 370 & 1620 & -0.5 \\
\hline 12 & 1200 & 5.08 & 160 . & 12.3 & 20.5 & 5.5 & 70 & 1120 & 11.7 & 268 & 1750 & 11.7 & 268 & 1750 & +0.0 \\
\hline 13 & 600 & 5.08 & 160 & 14.5 & 13 & 16.5 & 115 & 1100 & 20.4 & 355 & 1900 & 20.2 & 340 & 1750 & -0.2 \\
\hline 14 & 400 & 5.08 & 200 & 14.2 & 20 & 22 & 126 & 1150 & 26.9 & 360 & 1780 & 26.4 & 340 & 1700 & -0.5 \\
\hline 15 & 900 & 5.08 & 180 & 14.4 & 17.5 & 9 & 95 & 1130 & 13.0 & 320 & 1850 & 13.1 & 330 & 1860 & +0.1 \\
\hline 16 & 700 & 5.08 & 160 & 20.2 & 2 & 14 & 160 & 1140 & 18.1 & 495 & 1770 & 17.6 & 470 & 1580 & -0.5 \\
\hline 17 & 1200 & 5.08 & 160 & 14.2 & 25 & 6 & 85 & 1180 & 10.3 & 370 & 1860 & 9.9 & 335 & 1790 & -0.4 \\
\hline
\end{tabular}

C.R. = compression ratio $F / A=$ fuel-air ratio; $t_{0}=$ time of earliest predicted significant reaction; $t_{k}=$ time of occurrence of observed autoignition or knock; $t_{e}=$ time of occurrence of predicted autoignition or knock (zero of the time axis is arbitrarily set at $300^{\circ}$ crank angle); $p=$ cylinder pressure; $T=$ temperature of the end gas; $p_{i}=$ engine manifold pressure; $T_{i}=$ engine manifold temperature; S.A. = spark advance.

preliminary reactions were only three-quarters complete. and a $550 . \mathrm{N}$. blend with autoignition characteristies shown in Figure 3. The agreement be- 
tween the predicted and measured occurrence of autoignition was similarly good. All of the correlations are summarized in Figure 9 and in Table 2.

\section{Motored Engine Experiments}

In addition to the firing engine tests reported above, the results of similar tests obtained in a motored engine were used as a further check on the utility of the integration procedure. The results are also shown in Table 2 and are included in Figure 9. The temperatures shown for the motored engine were obtained from pressure and volume measurements via the perfect gas law.

As was the case for the firing engine, the agreement between the predicted and actual times of occurrence of autoignition is reasonable, particularly in view of the rapidly changing state of the

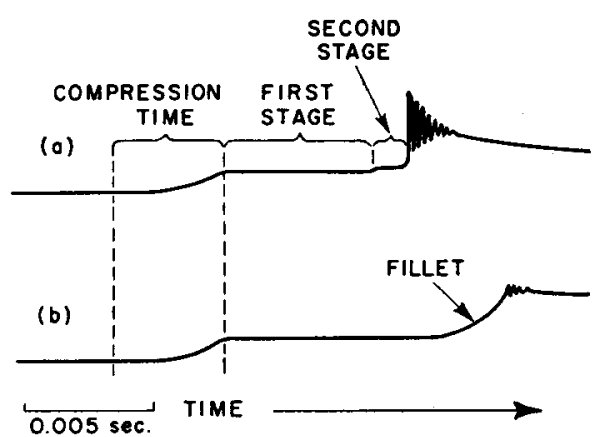

Fig. 10. (a) Two-stage ignition of $n$-heptane/air mixture. (b) Slow reaction, with pressure rise during the delay period, of diisobutylene. (M.I.T. Rapid Compression Machine.)

fuel-air mixture. For example, in the motored engine running at $900 \mathrm{rpm}$ the gas temperature is changing at the rate of $92,000^{\circ} \mathrm{F} / \mathrm{sec}$ at the time of autoignition, and the discrepancy between the measured and predicted temperatures at autoignition is $25^{\circ} \mathrm{F}$.

\section{Discussion}

The experimental success of the correlations shown is certainly no proof of the validity of the assumptions used for rationalizing the method. Nor is it intended to suggest that a more detailed (and presumably more general) method would not work as well, if such a procedure were available. However, for the two fuel-air mixtures which were tested, over a wide range of values of temperature, pressure and speed, the simple assumptions used yield a correlation which is well within the uncertainties of the experimental measurements.
Nevertheless, under other circumstances, interfering effects may arise. It is felt that these will be of two kinds. First is the question about rapid compression machine processes which do not occur at constant state, as shown in Figure 10. For the two-stage reaction in Figure 10a, it has been suggested that a separate integration be employed for each stage in succession. ${ }^{b}$ For this procedure to be successful it will be necessary to have good measurements of the increments in pressure and temperature which occur between the first and second stages. Efforts in this direction are under way.

A more complicated difficulty is anticipated for reactions which behave like Figure $10 \mathrm{~b}$. It has been suggested that correction factors ${ }^{17}, 18$ be employed to take account of the rising temperature and pressure during the delay period. However, this procedure seems rather like trying to force the definition of delay at constant state onto a reaction to which it obviously does not apply. A more serious objection lies in the photographic evidence $^{3,20}$ that these reactions are extremely non-homogeneous (geometrically speaking, at least). High speed photographs of the fillet region of reactions like that in Figure 10b have always shown the presence of one or more flame fronts. If we speak of delay in such a reaction, to which part of the charge do we refer, the portion which is inflamed or the part which is still unburned? The reasons for this behavior, which occurs with some fuels, are not yet clear.

The second large area of uncertainty lies with the possible behavior of fuel mixtures the components of which have greatly differing functions of reaction rate vs temperature and pressure. A particularly difficult problem is anticipated if the intermediate reaction products of the different fractions should interact ${ }^{10,}{ }^{21}$. This latter problem comes very close to that of the intricate behavior of additives ${ }^{22}, 23,24$.

\section{Concluding Remarks}

(1) Data are becoming increasingly adequate to permit at least exploratory attempts to correlate autoignition phenomena in terms of fundamental concepts.

(2) A hypothetical gross reaction of zero order seems to be adequate for using rapid compression machine data in the prediction of autoignition

${ }^{b}$ Private communications with E. B. Rifkin and C. Walcutt. 
(knock) in a motoring engine and in a firing engine. However, only two fuels were tested.

(3) Methods for accurate temperature measurement are required for this work, and recent developments are beginning to provide them.

(4) Additional data from motored engines would greatly augment the presented data. It is hoped that these will be forthcoming.

\section{Acknowledgment}

The work herein reported has been made possible by the support of the Ethyl Corporation for the rapid compression machine; the Coordinating Research Council, Inc., the Shell Oil Company, and the Office of Ordnance Research, U. S. Army have generously supported the continuing development of the sound-velocity temperature measurement technique. The motored engine results were contributed by E. B. Rifkin and C. Walcutt, Ethyl Corporation.

\section{REFERENCES}

1. Rögener, H.: Zeitschrift für Elektrochemie und angewandte physikalische Chemie, 58, 389 (1949).

2. Scheuermeyer, M., and Steigerwald, H.: MTZ Motortechnische Zeitschrift, 5, 229 (1943).

3. Taylor, C. F., et al.: S. A. E. Trans., 4, No. $2,232(1950)$.

4. Teichmans, H.: Zeitschrift für Elektrochemie und angewandte physikalische Chemie, 47, Nr. 4, 297, (1941).

5. Jost, W.: Third Symposium on Combustion, Flame and Explosion Phenomena, p. 424. Baltimore, The Williams \& Wilkins Co., 1949.

6. Tizard, H. T., and Pye, D. R.: Phil. Mag., 1, Series 7, 1094, (1926).

7. Johnston, R. C.: Thesis, S. M., M. I. T., 1952.

8. Levedahl, W. J., and Howard, F. L.: Ind. \& Eng. Chem., 43, 2805 (1951).

9. Pastell, D. L. : S. A. E. Trans., 4, 571, (1950).

10. Walcutt, C., Mason, J. M., and Rifkin, E. B.: Ind. \& Eng. Chem., 46, 1029 (1954).

11. Anon.: Four Methods for Measuring End Gas Temperature. Coordinating Research Council, Inc., N. Y., 1953.

12. Livengood, J. C., Rona, T. P., and Baruch, J. J.: J. Acous. Soc. Am., 26, 824, (1954).

13. MacPherson, J. H., Jr.: Thesis, Ph.D., Stanford University, June, 1946.

14. Strickland-Constable, R. F.: Third Symposium on Combustion, Flame and Explosion Phenomena, p. 279. Baltimore, The Williams \& Wilkins Co., 1949.
15. Davis, W. C., ет al.: A Comparison of the Intermediate Combustion Products in an Engine With and Without Ignition. To be published in S. A. E. Trans., 63 (1955).

16. Downs, D., Street, J. C., and Wheeler, R. W.: Fuel, 32, 279, (1953)

17. Beckers, A.: Motortechnische Zeitschrift, 14 , Nr. 12, 345 (1953).

18. SснміDт, F. A. F.: Verbrennungsmotoren, Thermodynamische und versuchsmässige Grundlagen unter besonderer Berücksichtigung der Flugmotoren, p. 310. Berlin, Springer-Verlag, 1945.

19. Maccormac, M., and Townend, D. T. A.: J. Chem. Soc. (London), 238 (1938).

20. Livengood, J. C., and Leary, W. A.: Ind. \& Eng. Chem., 49, 2797 (1951).

21. Mason, J. M., JR., and Hegselberg, H. E.: S. A. E. Trans., 62, 141 (1954).

22. Street, J. C.: S. A. E. Trans., 61, 442 (1953).

23. Chamberlain, G. H. N., and Walsh, A. D.: Proc. Roy. Soc., 215, 175 (1952-53).

24. Hoare, D. E., and Walsh, A. D.: Proc. Roy. Soc., 215, 454 (1952-53).

Discussion by L. B. Shore*

Messrs. Livengood and $\mathrm{Wu}$ offered the following equation to predict the time when knock would occur during the combustion of a fuel-air mixture:

$$
1=\int_{t=0}^{t=t_{e}} \frac{d t}{\tau}
$$

where $\tau=$ the delay time at a particular pressure and temperature

$$
\begin{aligned}
& t=\text { time } \\
& t_{e}=\text { time of knock }
\end{aligned}
$$

The same equation was derived independently at the Esso Laboratories some time ago as part of an effort to develop a useful and practical tool to aid in the understanding of the various combustion problems in Otto cycle engines. The thinking which led to the equation was quite similar to that of the authors.

An attempt was made to check the equation by a method essentially similar to that employed by the authors. This involved using it to predict the time of knock for two fuels of radically different anti-knock quality, namely, $n$-butane and $n$ heptane when each was being used at its own knock limited compression ratio. The knock limited compression ratio data were obtained from information presented by Campbell et al. $\dagger$ A spark timing of $17^{\circ} \mathrm{BTC}$ was assumed for both fuels.

* Esso Research and Engineering Company.

† J. M. Campbell, W. G. Lovell, and T. A. Boyd: SAE Journal, 76, 163 (1930). 
Values of delay time were obtained with rapid compression machine data of Roegner.t The pressures and temperatures needed were estimated by assuming: (1) a polytropic exponent of 1.3 for air, (2) a linear pressure rise from the time the spark fired to the time of peak pressure development, and (3) perfect mixing and vaporization of the fuel.

In spite of the fact that the two fuels in question differ considerably in octane number and therefore also in knock limited compression ratio (KLCR), the equation predicts the same time of knock for both as shown by the following data:

\begin{tabular}{crcc}
\hline Fuel & $\begin{array}{c}\text { Motor } \\
\text { Octane } \\
\text { Number }\end{array}$ & KLCR & $\begin{array}{c}\text { Time of Knock } \\
\text { Predicted by Equation }\end{array}$ \\
\hline n-Butane ..... & 91 & 6.4 & $\sim 10^{\circ} \mathrm{ATC}$ \\
$n$-Heptane .... & 0 & 2.8 & $\sim 10^{\circ} \mathrm{ATC}$ \\
\hline
\end{tabular}

This is what might be anticipated with both fuels being burned in engines set at their respective KLCR's. In addition, the time of $10^{\circ} \mathrm{ATC}$ predicted for knock is quite reasonable with the spark set to fire at $17^{\circ} \mathrm{BTC}$.

In view of the relative crudeness of the check method and the simple theories involved in the derivation, it was thought that these surprisingly good results were probably due, in some degree, to compensating errors. It was felt that the equation would probably not be too accurate mainly because its derivation assumes that the critical concentration of the knock producing species is independent of temperature and/or pressure. A priori, this assumption seems rather unlikely.

$\ddagger$ H. Roegner: U. S. Govt. Tech. Oil Mission Microfilm Reel 242; Photo Duplication Service, Library of Congress (1945).
However, in view of the refined experimental work done by the authors, it seems possible that this equation does accurately describe the processes leading to knock, at least for normal paraffins. One reason for this may be the fact that the largest contribution to the integral is made near the pressure and temperature of knock. Thus, the lack of dependence of the critical concentration on pressure and temperature need be true only over a short range of pressure and temperature. Regardless, it is anticipated that the form of the equation is probably right and if rewritten as follows might prove useful in the extrapolation, correlation, and interpretation of experimental results obtained from engines:

$$
1=\int_{t=0}^{t=t_{e}} \frac{d t}{\phi(T, P)}
$$

where $\phi(T, P)=$ an empirical function of temperature and pressure obtained from engine experiments.

The authors are to be congratulated for their efforts, theoretical as well as experimental, and it is to be hoped that they will continue their work. A numerical attack on the knock problem, even if semi-empirical in nature, could be of great help in understanding many of the everyday problems encountered with Otto cycle engines. Some of the important practical questions which could be approached much more rationally with this analytical treatment as a background are: (1) What is the mechanism by which combustion chamber deposits affect octane requirement and power loss? (2) What are the real differences among fuels of different anti-knock sensitivity? (3) What happens when surface ignition occurs before or after the spark is fired? (4) What causes engine speed to influence the anti-knock rating of fuels? and (5) What are the effects of fuel additives?

\title{
COMBUSTION OF HYDROGEN AND CARBON MONOXIDE AS RELATED TO KNOCK
}

\author{
By W. F. ANZILOTTI AND V. J. TOMSIC
}

\section{Introduction}

Extensive studies of preknock reactions of hydrocarbon fuels have been conducted by many investigators both in engines and in heated bombs or tubes. These investigations have resulted in advances in the chemistry of hydrocarbon com- bustion, but also have demonstrated that hydrocarbon-oxygen reactions are extremely complex.

In view of the indications in the literature ${ }^{1,2}$, 3. 4 that hydrogen-oxygen interaction may constitute a very important step common to most hydrocarbon-oxygen reaction mechanisms, and 